\title{
Vibrio splendidus O-antigen structure: A trade-off between virulence to oysters and resistance to grazers
}

\author{
Oyanedel Daniel 1, Labreuche Yannick 2, 3, Bruto Maxime 2, 3, Amraoui Hajar ${ }^{1}$, Robino Etienne ${ }^{1}$,

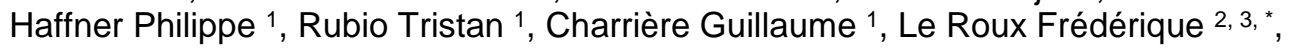 \\ Destoumieux-Garzón Delphine ${ }^{1,{ }^{*}}$
}

1 IHPE, Univ Montpellier, CNRS, Ifremer, Université de Perpignan Via Domitia; Montpellier, France

2 Ifremer, Unité Physiologie Fonctionnelle des Organismes Marins, ZI de la Pointe du Diable, CS 10070;

F-29280 Plouzané, France

${ }^{3}$ Sorbonne Universités, UPMC Paris 06, CNRS, UMR 8227, Integrative Biology of Marine Models,

Station Biologique de Roscoff, CS 90074; F-29688, Roscoff cedex ,France

* Corresponding authors : Frédérique Leroux, email address : frederique.le-roux@sb-roscoff.fr ;

Delphine Destoumieux-Garzon, email address : ddestoum@ifremer.fr

\begin{abstract}
:
A major debate in evolutionary biology is whether virulence is maintained as an adaptive trait and/or evolves to non-virulence. In the environment, virulence traits of non-obligatory parasites are subjected to diverse selective pressures and trade-offs. Here we focus on a population of Vibrio splendidus that displays moderate virulence for oysters. A MARTX (Multifunctional-autoprocessing repeats-in-toxin) and a type-six secretion system (T6SS) were found to be necessary for virulence toward oysters, while a region (wbe) involved in $\mathrm{O}$-antigen synthesis is necessary for resistance to predation against amoebae. Gene inactivation within the wbe region had major consequences on the O-antigen structure, conferring lower immunogenicity, competitive advantage and increased virulence in oyster experimental infections. Therefore, O-antigen structures that favor resistance to environmental predators result in an increased activation of the oyster immune system and a reduced virulence in that host. These trade-offs likely contribute to maintaining $\mathrm{O}$-antigen diversity in the marine environment by favoring genomic plasticity of the wbe region. The results of this study indicate an evolution of $\mathrm{V}$. splendidus toward moderate virulence as a compromise between fitness in the oyster as a host, and resistance to its predators in the environment.
\end{abstract}




\section{Introduction}

Parasite virulence encompasses two features of a disease producing capacity, i) infectivity, i.e. the capacity to colonize a host and ii) the ability to cause damage in a host (Pirofski and Casadevall, 2012). A major debate in evolutionary biology is whether virulence can evolve to non-virulence while maintaining the ability to provide other adaptive advantages (Bull and Lauring., 2014; Alizon and Michalakis., 2015; Cressler et al., 2016). On the one hand, as virulence affects host fitness, it may select for host resistance leading to a permanent non-virulence state. On the other hand, as a parasite evolves, it may counteract host resistance and maintain (or increase) virulence in a co-evolutionary arms race. For non-obligatory infectious agents, selection upon virulence traits will continue outside the host (Levin, 1996; Matz and Kjelleberg, 2005; Brown., et al 2012). This condition is exemplified by coincidental selection of bacterial genes involved in resistance to grazing in the environment and cytotoxicity to host immune cells, e.g., the macrophage (Adiba et al., 2010). However, experimental evolution in the context of single or multiple predators has revealed that the resultant bacterial resistance is frequently associated with an accompanying attenuation of virulence through pleiotropic 
effects on growth or infectivity (Friman et al., 2009; Mikonranta., et al 2012; Friman and Buckling, 2014), extending the long-standing debate regarding virulence evolution. Indeed, in the environment, virulence traits can be subjected to a multitude of pressures, yet relevant theories lack empirical data on the mechanisms of virulence gene acquisition, maintenance or loss (Ferenci., 2016).

Species of Vibrionaceae (herein named vibrio) are marine heterotrophic bacteria that are ecologically and metabolically diverse members of planktonic and animal-associated microbial communities (Takemura et al., 2014). The genus encompasses the well-studied human pathogen, $V$. cholerae, as well as some very important albeit less thoroughly characterized animal pathogens (Le Roux and Blokesch, 2018). Vibrio-associated diseases in Crassostreae gigas have been steadily rising over the past decade (Le Roux et al., 2015) and this oyster species is now considered as a model in which to explore vibrio disease dynamics in wild animals (Le Roux et al., 2016). Moreover vibrios have been subjected to population genetic analyses, which has allowed the delineation of functionally and genetically cohesive ecological populations (Cordero and Polz, 2014; Shapiro and Polz, 2014). This population genetic structure provides a framework for the mapping of disease properties, the analysis of vibrio ecological and evolutionary dynamics, and the interpretation of selective mechanisms. We previously showed that some vibrio populations are preferentially associated with oyster tissues compared to the surrounding water (Bruto et al., 2017). Within the diverse Splendidus clade, virulence represents an ancestral trait that has been lost in several populations (Bruto et al., 2018). We identified diverse loci that are necessary for virulence, resulting in population-specific mechanisms that converge to a common end: cytotoxicity to immune cells and immune evasion (Piel et al., 2019; Rubio et al., 2019). To date the non-virulence status of Splendidus-related strains has been related to gene loss (Bruto et al., 2018); however, whether and why gene acquisition could result in virulence attenuation remains to be determined. 
Here we focused on a population taxonomically assigned to the marine species $V$. splendidus and positively associated with oysters (Bruto et al., 2017). All members of this population were isolated in Spring, before oyster disease events. This sampling approach precludes biases associated with the selection of bacterial genotypes encoding high virulence potential (Bruto et al., 2017). We show that, while members of this population display moderate virulence, at least one strain is non-virulent. Two loci, a MARTX gene clusters and a type six secretion system (T6SS), were found necessary for virulence. A third locus (wbe), involved in O-antigen synthesis, distinguished between strains based on their combination of virulence and $\mathrm{O}$-antigen structure. Gene inactivation within the wbe region resulted in increased virulence, competitive advantage and lower immunogenicity in oyster, whereas it suppressed protection against grazing by marine amoebae. Our results suggest that a conversion of Oantigen structure resulting from wbe genes shuffling is involved in a trade-off between resistance to environmental grazing and virulence to oysters.

\section{Results}

Despite the presence of two virulence loci, $V$. splendidus strains can show a relatively moderate virulence toward oysters.

We previously demonstrated the coincidence of vibrio ecological population delineation with virulence for oyster (Bruto et al., 2018). Here we focused on three populations positively associated with oysters. Strains of $V$. splendidus (population \#23), associated to healthy oysters in spring, were significantly less virulent ( $82.1 \%$ mean survival rate $24 \mathrm{hpi}$, ANOVA, $p<0.05$ and Tukey HSD test) than populations isolated from diseased oysters in the summer (Bruto et al., 2017, 2018) (Fig. 1A). Moreover, contrasting 
virulence phenotypes were observed between strains of $V$. splendidus \#23 when generating KaplanMeier survival curves over 6 days (Fig. 1B). Indeed, only $40-60 \%$ of oysters injected with strains 4G4_4, 4D1_8 and 3T8_11 were alive at day 3, and generally remained viable until day 6 . To contrast with $V$. crassostreae and V. splendidus \#24 (Fig. 1A), we classify these strains as moderately virulent. By comparison, strain 4G1_8 had no significant effect on oyster survival (survival > $82 \%$, Log-rank p-value $=0,035$, Bonferroni corrected for 10 comparisons) over the 6 days.

We performed comparative genome analyses between the moderately virulent strains (3T8_11, 4D1_8, 4G4_4) and the non-virulent strain (4G1_8) to investigate the genetic bases of this moderately virulent phenotype. A total of 419 genes were found to be specific to the moderately virulent strains (maxLrap > 0.8; identity > 60\%) (Table S1). Among these genes, 38 clustered in two loci potentially involved in virulence. A first locus (rtxACHBDE, gene labels GV4G44_v1_300029 to 300034 in 4G4_4) encodes a putative toxin (MARTX, gene $r t x A)$, a putative acyltransferase $(r t x C)$, an uncharacterized protein $(r t x H)$, and a putative type I secretion system (rtxBDE) (Fig. S1A). The MARTXs found in 3T8_11, 4D1_8, 4G4_4 (5,088 amino acids) show $97.88 \%$ identities with the MARTX found in $V$. splendidus strain ZS185 (Bruto et al., 2018) and contain a core structure composed of two conserved regions at the amino- and carboxyl-termini, a cysteine-protease domain (CPD), a Ras/Rap1-specific endopeptidase (RRSP), an actin cross-linking domain (ACD), an $\alpha / \beta$ hydrolase ( $A B H$ ) and two other cysteine-protease effector domains (MCF) (Fig. S1B). We assessed genetically the importance of the MARTX encoding gene for $V$. splendidus \#23 virulence in strain 4G4_4 by inactivation of the $r \operatorname{txA}$ (rtxAi). Inactivation did not impair growth in culture media (Fig. S2) but increased significantly survival of infected oysters, from $71.7 \%$ to $82.5 \%$, when determined $24 \mathrm{hpi} \mathrm{(} \mathrm{p}<0.05)$ (Fig. 2). 
A second locus (GV4G44_v1_320001 to 320032 in 4G4_4) encodes a type VI secretion system (T6SS), a contact-dependent contractile nanomachine used by many Gram-negative bacteria as weapons against a variety of prokaryotic and eukaryotic organisms (Cianfanelli et al., 2016). The locus (herein named T6SS $4 G 44$ ) is organized into, at least, three operons containing genes involved in the structure and assembly of the contractile complex (Fig S3). Specifically, for the strain 4G4_4 next to the gene encoding a PAAR-motif protein (DUF4150 domain and 380 amino acid extension of unknown function), we identified a putative immunity system for nucleic acid degrading toxins. The putative effector (GV4G44_v1_320031 in 4G4_4) contains an AHH (Ala-His-His) nuclease domain found in bacterial polymorphic toxin systems (Zhang et al., 2011). In many bacterial models, T6SSs are involved in killing competing bacteria (Cianfanelli et al., 2016). Here, we did not observe inter-bacterial killing in vitro when using 4G4_4 as a predator and E. coli ML35p (Lehrer et al., 1988) as a prey (Fig S8). This result suggests that this $\mathrm{T}_{6 \mathrm{SS}_{4 G 4} 4}$ may not function in bacterial killing or are restricted to congeners. Alternatively, $\mathrm{T}_{6 \mathrm{SS}_{4 \mathrm{G}} \_4}$ expression could be restricted to specific conditions such as oyster infection. We also tested whether ${\mathrm{T} 6 S S_{4 G 4} 4}_{4}$ could mediate toxicity toward eukaryotic cells. This showed that the three moderately virulent strains of $V$. splendidus $\# 23$, as well as the non-virulent strain $4 G 1 \_8$, which lacks the $\mathrm{T}_{6 \mathrm{SS}}{ }_{4 \mathrm{G} 4} 4$ were all significantly cytotoxic, as they induced 25.9 to $51.3 \%$ hemocyte lysis over $18 \mathrm{~h}(\mathrm{p}<0.05)$, as opposed to $4.1 \%$ for the negative control $V$. tasmaniensis LMG20012 ${ }^{\top}$ (Fig S4A). Consistent with this observation, we found that inactivation of vipA in 4G4_4 (GV4G44_v1_320017), which encodes a component of the $\mathrm{TCSS}_{\# 23}$ contractile sheath, did not alter strain cytotoxicity, in

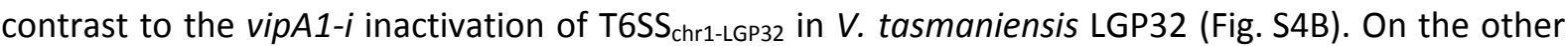
hand, the 4G4_4 vipA-i mutant showed attenuated virulence, as determined by a significant increase in oyster survival after vibrio injection, from $71.7 \%$ (wild-type $4 \mathrm{G} 4 \_4$ ) to $90.8 \%$ (4G4_4 vipA-i), $\mathrm{p}<0.05$ 
(Fig. 2). Hence, the presence of $\mathrm{T}_{6 \mathrm{SS}_{4 G 4} 4}$ affects virulence in the oyster, although its molecular mechanisms and cellular target(s) remain to be determined.

\section{Specific O-antigen structure antagonizes with $V$. splendidus virulence}

The O-antigen is a highly diverse structure of the lipopolysaccharide (LPS) molecules, and is displayed at the outer surface of Gram-negative bacteria. In V. splendidus, the wbe region involved in O-antigen synthesis was previously shown to exhibits extensive genetic diversity (Wildschutte et al., 2010). Here, we found that the moderately virulent strains of $V$. splendidus \#23 presents a wbe region structure (GV4G44_v1_410010 to GV4G44_v1_370009 in 4G4_4) that highly differs from that of the strain 4G1_8 (Table 1). To assess the possible consequences of wbe genetic organization on O-antigen structure, we analyzed the electrophoretic profiles of the LPS expressed by four strains of $V$. splendidus \#23. All LPS were of smooth type (Pupo and Hardy, 2007), as indicated by the typical ladder-like electrophoretic profiles of molecules containing different numbers of O-antigen repeating units (Raetz and Whitfield, 2002)(Fig. 3A). Short-chain molecular species containing only lipid A and core oligosaccharides migrated to the bottom of the gel, and were observed in all bacterial strains. However, several major differences were observed between the non-virulent strain $4 \mathrm{G} 1 \_8$ and the three moderately virulent strains (4G4_4, 3T8_11 and 4D1_8). First, the non-virulent 4G1_8 displayed an LPS of higher molecular weight with a lower number of monosaccharide residues per O-antigen repeating unit, as indicated by the tighter spacing between bands (Fig. 3A). Second, the LPS profile of all moderately virulent strains showed a prominent band of molecules of moderate size that may indicate the attachment to the core of a fixed number of O-antigen repeating units, or of an oligosaccharide side chain. In contrast to the polysaccharide moieties, no difference could be 
evidenced in the Lipid A anchor, as determined by MALDI-TOF-MS (Fig S5). To determine the functional consequences of such distinct LPS structures, we compared the ability of $V$. splendidus \#23 strains to bind to cytochrome $\mathrm{C}$, a cationic molecule that binds to the negatively-charged membranes of bacteria (Saar-Dover et al., 2012; Cullen et al., 2015). Cytochrome C bound significantly more to the nonvirulent 4G1_8 $(80.8 \%)$ than to the three moderately virulent strains, which all showed a similar degree of binding ( 25.3 to $34.6 \%$ ), $p<0.001$ (Fig. 3B). This result strongly suggests that genetic diversity in the wbe region of $V$. splendidus \#23 strains determines strain 0 -antigen structure, with consequences on the strain's ability to interact with macromolecules (Fig. 3B).

The importance of the wbe region for O-antigen synthesis and strain serotypes was further addressed genetically. To this aim, a gene encoding a glycosyltransferase (epsE, GV4G44_v1_370043 in 4G4_4) was inactivated in two strains. The LPS structure of the epsE-i mutant showed a reduced number of monosaccharides per repeating units (tighter spacing of the bands) as well as a higher molecular weight than the wild-type 4G4_4 (Fig. 3A), confirming that the wbe region determines the O-antigen profile. Moreover, epsE inactivation in strain 4G4_4 was sufficient to increase cytochrome $\mathrm{C}$ binding from $33.7 \%$ in the wild type strain $4 \mathrm{G} 4 \_4$ to $71.6 \%$ in epsE-i $(p<0.001)$ reflecting important changes in the bacterial surface properties. Identical phenotypes on O-antigen structure and binding capacity were obtained for the epsE-i mutant derived from another moderately virulent strain, 4D1_8 (Fig S6).

We next explored the effect of epsE inactivation on virulence. The epsE-i mutant was found significantly more virulent that the wild type strain 4G4_4 in oyster experimental infections. Indeed, oyster survival rate dropped from $71.7 \%$ when injected with wild type $4 \mathrm{G} 4$ _4 down to $58.8 \%$ upon 4G4_4 epsE-i injection, $p<0.05$ (Fig. 2). In addition, the epsE-i mutant showed a significant competitive advantage over their wild-type parents, 4G4_4 and 4G1_8 in oyster colonization, as indicated by competitive index values > 0.5 (Fig. 4A). 
Because the O-antigen is a well-known determinant of bacterial immunogenicity (Chatterjee and Chaudhuri, 2011), we next asked whether the oyster immune response depended upon the O-antigen structure. Cells of 4G4_4 wild type and epsE-i mutant were injected into juvenile oysters after removing all traces of culture medium (potentially immunogenic). Oyster immune gene expression was then measured by RT-qPCR 2 hpi to capture the oyster's early response to infection. We selected 8 genes (IL 17-1, IL 17R, NFkB, MyD88, TNF-14, CgLBP, CgBPI, CgBigDef-1) involved in recognition, immune signaling and pathogen control that were previously shown to respond to vibrio infections (Gonzalez et al., 2007; Rosa et al., 2011; Rubio et al., 2019; Sun et al., 2019). Only genes encoding cytokines or involved in signaling pathways, namely IL 17-1, MyD88 and TNF-14, were significantly more induced by injection of the wild type 4G4_4 cells relative to an injection of sterile seawater (SSW) (Fig. 4B; Fig. S7). Interestingly none of these important immune pathways was significantly induced by the 4G4_4 epsE-i mutant at this early time point. Therefore, the LPS structure harbored by the moderately virulent strains appears as more immunogenic than that of the corresponding epsE-i mutant. This lower immunogenicity could be responsible for the higher competitiveness and virulence of the 4G4_4 epsE-i mutant in oyster experimental infections (Fig 2 and 4A).

\section{Trade-off between immunogenicity and grazing resistance is mediated by 0 -antigen structure}

As non-obligate parasites, vibrios can encounter a variety of hosts and predators in the marine environment. To determine whether the O-antigen structure of $V$. splendidus $\# 23$ affects other biotic interactions, we tested each strain`s resistance to grazing by a marine amoeba isolated from the oyster environment (Robino et al., 2019). The wild-type 4G4_4 was resistant to grazing by Vannella sp. AP1411, as indicated by a stable relative fluorescence of the bacterial strain up to ten days after the 
beginning of the grazing experiment (Fig 5A). In agreement Vannella sp. AP1411 did not grow on a 4G4_4 grazing lawn (Fig 5B). In contrast, the epsE-i derivative was significantly grazed, as indicated by the decrease of the relative fluorescence down to $46.8 \%(p<0.05)$ of the vibrio lawn (Fig 5A) and enabled a significant amoeba growth $\left(407\right.$ cells $/ \mathrm{mm}^{2}, \mathrm{p}<0.05$ ) after 12 days (Fig 5B). The grazersusceptible control V. tasmaniensis LMG $20012^{\top}$ was almost completely grazed in the same time span, giving rise to a significant level of amoeba growth at day 12 (651 cells $\left./ \mathrm{mm}^{2}, \mathrm{p}<0.05\right)$ (Fig.5). Taken altogether, these results show that the LPS structure present in moderately virulent strains of $V$. splendidus \#23 is protective against amoeba grazing but immunogenic during the interaction with oysters.

\section{Discussion}

In the environment, vibrios are exposed to a diversity of selective pressures, that may have effects on their virulence (Cui et al., 2015; Shapiro et al., 2016; Roig et al., 2018; Sakib et al., 2018; López-Pérez et al., 2019) Here, we identified in a population of vibrios, trade-offs between traits needed for resistance to a grazer and traits involved in virulence to oysters. Illustrating the "conflicting selection hypothesis" (Mikonranta et al., 2012), an O-antigen structure conferring resistance to predation by marine amoebae showed increased immunogenicity, and lower competitiveness and virulence in oysters, showing that selection in the outside-host environment might conflict with optimized pathogenicity.

V. splendidus population \#23 has been previously described as preferentially associated with oyster tissues, suggesting that oysters represent a permissive habitat for this population. This is supported here by the ability of all tested strains to kill the oyster hemocytes and thus potentially evade the host 
immune response. To date cytotoxicity toward the oyster hemocytes has been described as a common trait of virulent vibrios, although based on population specific molecular determinants (Piel et al., 2019; Rubio et al., 2019). The present study shows that dampening of oyster cellular defenses is a trait not restricted to virulent populations but shared by moderately and non-virulent strains that constitute the microbiota of healthy oysters.

Although less virulent than vibrios associated to disease (V. splendidus \#24 and V. crassostreae), some V. splendidus \#23 strains were able to affect oyster survival in experimental infections. This moderate degree of virulence results at least in part from the acquisition of two loci encoding effector delivery systems, a MARTX gene complex and a T6SS. The MARTX toxins are multifunctional effector cargo translocation, processing and delivery machines that can deliver functionally diverse cytopathic bacterial effectors to target eukaryotic cell (Satchell, 2015). In V. splendidus \#23, MARTX effector domains are potentially involved in: i) modulation of small GTPases and manipulation of host cell signaling (RRSP); ii) disruption of cytoskeletal integrity (ACD) ; iii) inhibition of endocytic trafficking and autophagy (ABH); and iv) induction of apoptotic cell death (MCF) (Gavin and Satchell, 2015). The $V$. splendidus \#23 MARTX share the same overall structure as V. vulnificus MARTX type III, i.e. an MCF domain, an $\mathrm{ABH}$ domain, and then a second copy of MCF follow the ACD domain. In V. vulnificus the MARTXs appear to be essential for protection both from fish phagocytic cells and from predation by amoeba (Lee et al., 2013) .

The T6SS nanomachines and its effectors are highly diverse in vibrios, acting against bacterial competitors (Unterweger et al., 2014), amoeba or phagocytic cells during an intracellular stage (Ma et al., 2009) or directly by contact with the target eukaryotic cell. Our cytotoxicity assays suggest that in $V$. splendidus \#23, the T6SS does not target oyster hemocytes, in contrast to $V$. tasmaniensis or $V$. 
crassostreae (Piel et al., 2019; Rubio et al., 2019). The presence of toxin and immunity modules in the T6SS loci would rather indicate anti-bacterial activity. However the T6SS might also be tightly regulated transcriptionally or post-translationally by lifestyle of the bacterium, or by membrane damage due to conjugation or membrane-targeting antibiotic (Ho et al., 2013). Indeed a within-host restricted expression was previously observed in $V$. tasmaniensis for $\mathrm{T}_{6 \mathrm{SS}} \mathrm{Chr2-LGP32}_{\text {, one of the two chromosomal }}$ T6SS identified in this population (Rubio et al., 2019). Future work should explore the environmental conditions necessary for its expression and function in order to formally demonstrate its role in interbacteria competition. Overall, the selection of specific effector domains within the T6SS or MARTX loci may arise as a result of the evolutionary arms race between bacteria, competitors and predators and could have correlative effects on bacterial virulence, hence supporting the "coincidental selection hypothesis" (Levin, 1996; Matz and Kjelleberg, 2005; Brown et al., 2012).

Various biotic interactions can also lead to a trade-off on virulence (Friman et al., 2009; Mikonranta et al., 2012; Friman and Buckling, 2014). We showed here that the acquisition of genes involved in the synthesis of the LPS O-antigen confers a phenotype resistant to predation by an amoeba but results in a reduced virulence in the oyster. LPS is major components of the outer membrane in Gram-negative bacteria. These molecules are composed of a conserved lipid structure that is embedded in the outer membrane, and a polysaccharide referred to as the O-antigen (Raetz and Whitfield, 2002). O-antigen structures are highly variable across strains of a species (Seif et al., 2019) and the wbe region was identified as a hypervariable locus in V. splendidus, contributing to structural variations of O-antigen (Wildschutte et al., 2010). Wildschutte et al. observed extensive gene shuffling in the wbe region, which provides a means for $\mathrm{O}$-antigen structure selection. However, they did not find any predominant serotype within hosts but conversely observed closely related serotypes, expressing the same Oantigen, among different hosts (Wildschutte et al., 2010), which raises the questions about 
whether/how the selection of O-antigen structures occurs outside the host. In nature this outer membrane structure directly interacts with ambient surfaces in the environment and, thus is subject to environmental selective pressures (Wildschutte et al., 2004; March et al., 2013). Indeed O-antigens constitute a first line of defense against predators (Simkovsky et al., 2016) and have been shown to mediate antimicrobial resistance (Band and Weiss, 2015). Here we found that mutation of the wbe region was detrimental to the resistance of amoeba grazing. Indeed, a $V$. splendidus \#23 lost its resistance upon mutation of the wbe region. Therefore, selective forces exerted by environmental predators may have favored the maintenance of this wbe encoded O-antigen structure.

In the host, $\mathrm{O}$-antigens play a key role in both the activation of innate immunity and resistance to host immune effectors (Raetz and Whitfield, 2002). This dual function has important consequences on disease outcomes. In the rainbow trout (Oncorhynchus mykiss) pathogen Vibrio anguillarum, Oantigen polysaccharides were reported to determine the capacity to evade phagocytosis by skin epithelial cells (Lindell et al., 2012). In Vibrio vulnificus, O-antigen polysaccharides are protective against serum complement, playing a key role in virulence for eels (Amaro et al., 1997). Here, mutation of the wbe region yielded a modified O-antigen structure that significantly increased strain competitiveness and virulence. The O-antigen modification affected the polysaccharide structure and reduced strain immunogenicity, as indicated by the lack of induction of important oyster immune pathways involved in vibrio recognition (Rubio et al., 2019) during early infection stages. This result indicates that strains of $V$. splendidus \#23 with moderate virulence harbor an O-antigen structure easily recognized by the oyster immune system, leading to suboptimal colonization capacity. A trade-off between virulence and resistance to predators outside of host tissue was previously reported for Salmonella enterica O-antigen structure, which is under epigenetic control (Cota et al., 2015). In this species, the O-antigen is a receptor for phage, and resistance is acquired by phase variation of O- 
antigen chain length, i.e. phenotypic plasticity. Adaptations to phage predation involving trade-offs in evolutionary fitness and virulence have also been described for $V$. cholerae. Resistance to the lytic phage ICP2 results from mutations within either ompU, which encodes the major outer membrane porin, or its direct regulator toxR and results in virulence attenuation (Seed et al., 2014).

Epidemiological success of non-obligate parasites depends on their environmental persistence in addition to the ability to produce major virulence factors. In complex microbial ecosystem such as the marine environment or the oyster microbiota, the outcomes for virulence trait selection can be positive (coincidental selection), neutral (relaxed selection), or negative (conflicting selection) (Mikonranta et al., 2012). It has been argued that high virulence resulting in rapid killing of the host can be maladaptive as it does not allow parasite niche maintenance by the parasite (Alizon and Michalakis, 2015). Our genomic and phenotypic data suggest that $V$. splendidus \#23 has evolved as a moderately virulent population with high fitness in its host, thereby supporting the theoretical prediction that moderate virulence can maximize parasite overall fitness (Alizon and Michalakis, 2015). 


\section{Experimental procedures}

\section{Strains, plasmid and primers}

Vibrio strains used in this study were V. splendidus 3T8_11, V. splendidus 4D1_8, V. splendidus 4G1_8, V. splendidus 4G4_4 (Bruto et al., 2018). Vibrio strains were cultured at $20^{\circ} \mathrm{C}$ in Luria Bertani medium (LB) supplemented with $0.5 \mathrm{M} \mathrm{NaCl}$ (LBS). For Vibrio splendidus strains carrying either the integrative suicide plasmid pSW23T (Demarre et al., 2005) or the pMRB-P LACGFP replicative plasmid (Le Roux et al., 2011), the culture media were supplemented with $5 \mu \mathrm{g} / \mathrm{mL}$ of $\mathrm{Cm}$. For strains carrying a pMRBPLACGFP replicative plasmid with a spectinomycin (Spc) resistance cassette, $100 \mu \mathrm{gL}^{-1} \mathrm{Spc}$ was used. Escherichia coli strains were cultured at $37^{\circ} \mathrm{C}$ in LB medium. Marine amoebae Vannella sp. AP1411 (Robino et al., 2019) was grown for 3 days prior experiments at $18^{\circ} \mathrm{C}$ in $70 \%$ sterile seawater $(70 \%$ SSW), , using E. coli SBS363 as a nutritive source. Other strains, plasmids and primers used are included in Tables S2-S3-S4.

\section{Animals}

For experimental infections, we used Crassostrea gigas diploid oysters from a batch of standardized Ifremer spats (NSI) produced from a pool of 120 genitors. Animals were from both sexes. For hemocyte cytotoxicity assays, hemolymph was collected from adults (18 months old) produced from a pool of 120 genitors (ASI). All oysters were produced at the Ifremer hatchery in Argenton, France.

\section{Experimental infections}

Experimental infections were performed at $20^{\circ} \mathrm{C}$, as previously described (Rubio et al., 2019). Juvenile oysters $\left(1.5-2 \mathrm{~cm}\right.$ ) were anesthetized for $3 \mathrm{~h}$. by immersion in seawater with $50 \mathrm{~g} \mathrm{~L}^{-1} \mathrm{MgCl}_{2}$ (Suquet et al., 2009). Stationary phase cultures $\left(20 \mathrm{~h}\right.$. at $20^{\circ} \mathrm{C}$ with agitation at $\left.150 \mathrm{rpm}\right)$ were prepared for 
injection into the adductor muscle. For survival curves, two groups of 20 individuals were used. Each animal received an intramuscular injection of stationary phase culture $\left(2 \times 10^{7}\right.$ CFU per animal) or an equivalent volume of fresh culture medium. Each group of injected oysters was placed in a separate tank containing $3 \mathrm{~L}$ of seawater. Mortalities were monitored at $24 \mathrm{~h}$ or daily for a 6 -day period. The non-parametric Kaplan Meier test was used to estimate log-rank, including Bonferroni p-value correction for multiple comparison. Each phenotyping was repeated twice. For gene-expression analysis, stationary phase culture were washed three times in sterile seawater (SSW) and adjusted to $2 \times 10^{8} \mathrm{CFU} / \mathrm{mL}$ before injection into oyster adductor muscle. For each condition tested, 40 oysters were injected with $100 \mu \mathrm{L}$ of the washed bacterial culture or SSW only. 4 pools of 10 oysters were collected at time 0 (untreated controls) and at $2 \mathrm{~h}$ post injection (hpi) for each experimental condition. Pools of oyster tissues were snap frozen in liquid nitrogen and pulverized with a bead mixer mill (Retsch MM400). Pulverized pools were kept at -80 until RNA extraction. Experimental infections were performed according to the Ifremer animal care guidelines and policy.

\section{Growth curves}

Strains from $-80^{\circ} \mathrm{C}$ stocks were plated on $\mathrm{LB} \mathrm{NaCl}$ agar plates and incubated at $20^{\circ} \mathrm{C}$ for $24 \mathrm{~h}$. Single colonies were used to seed LB NaCl broth. After overnight at $20^{\circ} \mathrm{C}$ with agitation at $150 \mathrm{rpm}$, cultures were adjusted to an $\mathrm{OD}_{600}$ of 0,1 in fresh $\mathrm{LB} \mathrm{NaCl} 0.5 \mathrm{M}$ broth. For each bacterial suspension, $300 \mathrm{ul}$ were disposed in triplicate in a 96 well platen and $O D_{600}$ was measured every 15 minutes in a TECAN infinite plate reader for $18 \mathrm{~h}$.

\section{Killing Assay}


Vibrios strains were grown at $20^{\circ} \mathrm{C}$ in LBS media containing $5 \mu \mathrm{g} \mathrm{LL}^{-1}$ chloramphenicol when needed and $E$. coli ML35p was grown at $37^{\circ} \mathrm{C}$ in LB media containing $100 \mu \mathrm{gL}^{-1}$ ampicillin.

Cultures of Predator and prey strains were normalized to an $\mathrm{OD}_{600}$ of 1 and mixed at a $\mathrm{MOI}$ of $10.50 \mu \mathrm{l}$ of cell suspension were spotted on a $0.45 \mu \mathrm{m}$ membrane (MF-Milipore ${ }^{\mathrm{TM}}$ MCE) placed in LBS agar to allow cell to cell contact and incubated at $20^{\circ} \mathrm{C}$ for $5 \mathrm{~h}$. Filters were recovered and bacteria resuspended in LBS media. CFU of surviving E. coli per milliliter was determined by plating serial dilutions and selective growth at $37^{\circ} \mathrm{C}$ on LB agar containing $100 \mu \mathrm{g} \mathrm{mL}-1$ ampicillin.

\section{Competitive index in mixed infections}

For competitive assays of mix infections, adult oysters (ASI) were anesthetized and injected as described above with a 1:1 mixture of strains $\left(2 \times 10^{7} \mathrm{CFU}\right.$ total $)$ in $\mathrm{LB} \mathrm{NaCl}$ medium. $24 \mathrm{hpi}, 8$ oysters per group were sampled and homogenized with an ULTRA-TURRAX ${ }^{\circledR}$ homogenizer after adding $1 \mathrm{~mL}$ of SSW per g of flesh. Tissue homogenates were serially diluted in SSW and plated onto TCBS agar plates. Colonies were randomly selected after $48 \mathrm{~h}$ at $20^{\circ} \mathrm{C}$ and tested by PCR with strain-specific primers (Table S4) to determine the ratio of strains present on each individual. Multiplex PCR with strain-specific primer couples 4G4_4F: 5'- TGCTATTGAGGAGGGACTGG-3'/4G4_4R: 5'CACCTGAACCCAAAAATCGT-3' and 4G1_8F:5'-CAGAACTCTCTGGGCATGTG-3'/4G1_8R: $\quad 5^{\prime}$ AAAATCACACCCGACTCGAC -3', were used to discriminate between strains 4G4_4 and 4G1_8. To discriminate between $4 \mathrm{G} 4 \_4$ and $4 \mathrm{G} 4 \_4 * e p s E-\mathrm{i}$, the external primers used for mutant control Ext*epsE-F: 5'- TCTCTGATGACTGCTCAACTG -3' and Ext*epsE-R: 5'- TAAATAGACACGAAGGACCC -3' were used to identify epsE-i strains from wild type. To discriminate between $4 \mathrm{G} 1 \_8$ and $4 \mathrm{G} 4 \_4$ epsE-i 
a first multiplex PCR was performed to differentiate between 4G4_4 and 4G1_8 strains and a second pcr with the epsE-i control primers to confirm that 4G4_4 identified colonies corresponded to espE-i mutants. The competitive index was calculated as the ratio of the strains in the input inoculum over the ratio of the strains in the output obtained after $24 \mathrm{hpi}$. Competitive indices were then log transformed. Significant differences from a hypothetical value of 0 (no fitness advantage between strains) were determined with a one sample Student's t-test.

\section{Molecular microbiology}

Vibrio strains were grown at $20^{\circ} \mathrm{C}$ in $\mathrm{LB} \mathrm{NaCl}$ medium. Escherichia coli strains were grown at $37^{\circ} \mathrm{C}$ in $\mathrm{LB}$ medium for cloning and conjugation experiments. Chloramphenicol $(\mathrm{Cm})$ at 5 or $25 \mu \mathrm{g} \mathrm{mL}^{-1}$ depending on the strain, Spectinomycin $(\mathrm{Spc})$ at $100 \mathrm{ug} \mathrm{mL^{-1 }}$, thymidine $(0.3 \mathrm{mM})$ and diaminopimelate $(0.3 \mathrm{mM})$ were added as supplements when necessary. Conjugations between E. coli and Vibrio were performed at $30^{\circ} \mathrm{C}$ as described previously (Le Roux et al., 2007). Gene inactivation was performed by cloning $500 \mathrm{bp}$ of the target gene in pSW23T (Demarre et al., 2005) and selecting on $\mathrm{Cm}(5 \mu \mathrm{g} / \mathrm{mL}$ ) the suicide plasmid integration obtained by a single recombination (Le Roux et al., 2009). Mutants were screened for insertion of the suicide vector by PCR using external primers flanking the different targeted sequence for plasmid insertion (Table S4). To label bacteria with fluorescent emission, strains were transformed with the pMRB plasmid containing the green fluorescent protein ( $g f p$ ) gene known to be stable in Vibrio spp (Le Roux et al., 2011) resulting in a constitutive expression from a $\mathrm{P}_{\text {lac }}$ promoter under chloramphenicol or spectinomycin selection.

\section{Grazing assay and monitoring of amoeba growth}


To prepare the co-culture of GFP-expressing vibrios and amoebae, $1 \mathrm{~mL}$ of vibrio overnight culture (3 x $10^{9} \mathrm{CFU} / \mathrm{mL}$ ) was mixed with $100 \mu \mathrm{L}$ of a 3 day-old Vannella sp. AP1411 culture ( $5 \times 10^{5}$ cells / mL) resuspended in $70 \%$ SSW. For the control without amoeba, the vibrio culture was mixed with $100 \mu \mathrm{L}$ of $70 \%$ SSW. For grazing experiments, $500 \mu \mathrm{L}$ of $70 \%$ SSW containing $1 \%$ agar were deposited in the wells of a 24-well plate (transparent flat bottom). Each well was covered with $50 \mu \mathrm{L}$ of the mixed vibrio/amoeba cultures and let dry for $4 \mathrm{~h}$ at $20^{\circ} \mathrm{C}$ under a sterile laminar flow. The 24-well plates were then incubated at $18^{\circ} \mathrm{C}$ in a humid atmosphere. GFP fluorescence intensity was measured daily over 12 days using a TECAN plate reader ( $\lambda$ ex $480 \mathrm{~nm} / \lambda \mathrm{em} 520 \mathrm{~nm}$ ). To estimate the effect of the amoebae grazing activity on the abundance of GFP-expressing vibrios, the fluorescence intensity of the wells containing amoebae was compared with the fluorescence of vibrios lawn without amoebae, and expressed as a ratio. Each condition was performed in technical triplicates, and the more representative experiment is depicted out of at least three independent experiments. Error bars represent the standard error of the mean \pm SD. Statistical analysis was performed using RM-ANOVA and Tukey's HSD comparison test.

The proliferation of Vannella sp. AP1411 was monitored at days 6, 9 and 12 in grazing assays. Amoebae were directly imaged by phase-contrast microscopy and enumerated in triplicate for each condition. Every experiment was performed in technical triplicates, and the more representative experiment is depicted out of at least three independent experiments. Error bars represent the \pm SD. Statistical analysis was performed using ANOVA, $p<0.001$ and Tukey HSD test.

\section{LPS isolation and molecular characterization}

LPS were prepared from $4 \mathrm{~L}$ of stationary phase cultures of vibrios growth in $\mathrm{LB} \mathrm{NaCl} 0.5 \mathrm{M}$. Cultures were centrifuged at $1500 \mathrm{~g}$ for $20 \mathrm{~min}$ and bacterial pellets were washed with SSW before fixation with 
$2 \%$ paraformaldehyde $\left(18 \mathrm{~h}\right.$ at $\left.4^{\circ} \mathrm{C}\right)$. Fixed bacteria were centrifuged ( $3000 \mathrm{~g}$ for $20 \mathrm{~min}$ ) and washed twice with 0.1 M Phosphate Buffer Saline before shipping in dry ice to LPS Bioscience, University Paris Sud, 91400 Orsay France. LPS structures were characterized by electrophoresis and/or MALDI-TOF-MS by as described in (Trent et al., 2012). Briefly, Lipids A were isolated from lyophilized bacteria by mild acid hydrolysis followed by an extraction with an appropriate chloroform-methanol-water mixture. Bacterial lysates were treated with Proteinase $\mathrm{K}$ and loaded to a $4-15 \%$ polyacrylamide gel for electrophoresis. Gels were silver-stained. MALDI-TOF-MS analysis was performed in negative-ion [MH]- / linear mode. A purified lipid A from Escherichia coli was used as a standard for external calibration of $V$. splendidus lipids A mass-spectra.

\section{RT -qPCR monitoring of immune gene expression}

Total RNA was extracted from $10 \mathrm{mg}$ of pulverized oysters using Direct-zol RNA extraction kit (Zymo research). cDNA was synthetized using M-MLV RT (Invitrogen Inc.) with $1 \mu \mathrm{g}$ of RNA and $250 \mathrm{ng}$ of random primers (Promega). Real-time qPCR was performed on $40 \mathrm{ng} / \mu \mathrm{l}$ of $\mathrm{CDNA}$ at the $\mathrm{qPHd}$ plateform of qPCR in Montpellier with the Light-Cycler 480 System (Roche) and using the oyster gene specific primers (Table S4). Relative expression was calculated using the $2^{-\Delta \Delta \mathrm{Ca}}$ method (Pfaffl, 2001) , with normalization to the $C$. gigas EF1- $\alpha$ (GenBank AB123066). One-way ANOVA followed by Tukey HSD test for multiple comparisons was used to analyze the data.

\section{In vitro cytotoxicity assays}

Hemolymph was collected from the oyster adductor muscle sinus using a 2-mL ice cold-syringe equipped with a $23-\mathrm{G}$ needle to prevent cellular aggregation. Hemocytes were counted in a KOVA ${ }^{\circledR}$ 
slide and plated onto 96 well-plates to create a cell monolayer $\left(2 \times 10^{5}\right.$ cells per well). After $1 \mathrm{~h}$ at $20^{\circ} \mathrm{C}$, plasma was removed and $5 \mu \mathrm{g} \mu \mathrm{l}^{-1}$ Sytox Green (Molecular Probes) diluted in $200 \mu \mathrm{l}$ sterile seawater was added to each well. Cell-free hemolymph (plasma) was obtained by centrifugation $(3,000 \mathrm{~g}, 15 \mathrm{~min}$, $4^{\circ} \mathrm{C}$ ) and filtration through a 0,2 $\mu \mathrm{m}$ syringe filter. Vibrios were centrifuged and resuspended in the cell free plasma for opsonization ( 60 minutes at $20^{\circ} \mathrm{C}$ ). The $\mathrm{OD}_{600}$ of the vibrio suspension was normalized in SSW to $1\left(10^{9} \mathrm{CFU} \mathrm{mL}^{-1}\right)$ and vibrio were added to the wells at a $\mathrm{MOI}$ of 50:1. Hemocytes were incubated at $20^{\circ} \mathrm{C}$ for $18 \mathrm{~h}$ after which the Sytox fluorescence was measured ( $\lambda$ ex $480 \mathrm{~nm} / \lambda$ em $550 \mathrm{~nm}$ ) using a TECAN infinite microplate reader. Fluorescence intensity was compared to the total cytolysis determined in control wells where hemocytes were lysed by adding $0.1 \%$ Triton X-100. An ANOVA followed by a Tukey's HDS test was perform on the data.

\section{Cytochrome $\mathrm{C}$ binding assay}

Stationary phase cultures $\left(20 \mathrm{~h}, 20^{\circ} \mathrm{C}, 150 \mathrm{rpm}\right)$ were wash twice by centrifugation $\left(1500 \mathrm{~g}, 20^{\circ} \mathrm{C}\right)$ with $20 \mathrm{mM}$ MOPS buffer $(\mathrm{pH} 7,2)$ supplemented with sucrose for a final osmolarity of 450 mOsm to make it compatible with the hyper saline environment of marine bacteria but to eliminate interfering charged salts. After washing by centrifugation (1500g, $20 \mathrm{~min})$, bacterial pellets were suspended in MOPS sucrose buffer and the suspension was adjusted to an $\mathrm{OD}_{600}$ of 6 . Cytochrome $\mathrm{C}$ solution was prepared in MOPS-Sucrose buffer to a concentration of $5 \mathrm{mg} \mathrm{mL}^{-1}$. Then, $900 \mu \mathrm{L}$ of bacterial suspension were placed in $1.5 \mathrm{~mL}$ polypropylene microcentrifuge tubes with $0.5 \mathrm{mg} \mathrm{mL}^{-1}$ cytochrome c. Tubes were incubated for $15 \mathrm{~min}$ at $20^{\circ} \mathrm{C}$ and then centrifuged at $6000 \mathrm{~g}$ at room temperature for $15 \mathrm{~min}$. The $\mathrm{OD}_{530}$ of the supernatants was measured in a TECAN microplate reader ( $300 \mu \mathrm{L}$ transferred in triplicates 
to 96 wells plates). The percentage of bound cytochrome $\mathrm{c}$ to bacteria was calculated relative to the $\mathrm{OD}_{530}$ value of a $0.5 \mathrm{mg} / \mathrm{mL}$ cytochrome c control solution not exposed to bacteria.

Acknowledgements. We warmly thank Prof. Edward G. Ruby (University of Hawai'i, USA) for critical reading of the manuscript. We thank Prof. Hervé Cottet from the IBMM (Montpellier, France), Dr. Jeremie Vidal-Dupiol and Dr. Yannick Gueguen from IHPE (Montpellier, France) as well as Dr. Agnès Delmas from the CBM (Orléans, France) for fruitful discussions. We are indebted to Marc Leroy from IHPE for precious technical assistance, to Dr. Martine Caroff and Dr. Alexey Novikov from LPS biosciences (Orsay, France) for lipopolysaccharide characterization, and to Philippe Clair at the qPHD platform/Montpellier genomix (Montpellier, France) for access to qPCR. We thank Bruno Petton, Matthias Huber and Jacqueline Le Grand from the Ifremer for providing standardized oyster spats for experimental infections and adults for cellular biology. This work was supported by the European Union's Horizon 2020 Research and Innovation Program Grant Vivaldi 678589; the CNRS, PEPS Blanc 2016 (project Like Inhospitality); CONICYT PFCHA/Doctorado En El Extranjero Becas Chile/201672170430 to D.O.; AMIBADAPT project funded by LABEX CeMEB; The Agence Nationale de la Recherche (Revenge project, ANR-16-CE32-0008-01) to F.L.R., and the University of Montpellier (Doctoral School Gaia; to E.R. and T.R.). This study is set within the framework of the "Laboratoires d'Excellence (LABEX)" Tulip (ANR-10-LABX-41).

\section{Conflict of Interest}

The authors declare that there are no conflicts of interests related to this work 


\section{References}

Adiba, S., Nizak, C., van Baalen, M., Denamur, E., and Depaulis, F. (2010) From grazing resistance to pathogenesis: The coincidental evolution of virulence factors. PLoS One 5: 1-10.

Alizon, S. and Michalakis, Y. (2015) Adaptive virulence evolution: the good old fitness-based approach. Trends Ecol Evol 30: 248-254.

Amaro, C., Fouz, B., Biosca, E.G., Marco-Noales, E., and Collado, R. (1997) The lipopolysaccharide O side chain of Vibrio vulnificus serogroup E is a virulence determinant for eels. Infect Immun 65: 2475 LP - 2479.

Band, V.I. and Weiss, D.S. (2015) Mechanisms of Antimicrobial Peptide Resistance in Gram-Negative Bacteria. Antibiot (Basel, Switzerland) 4: 18-41.

Brown, S.P., Cornforth, D.M., and Mideo, N. (2012) Evolution of virulence in opportunistic pathogens: Generalism, plasticity, and control. Trends Microbiol 20: 336-342.

Bruto, M., James, A., Petton, B., Labreuche, Y., Chenivesse, S., Alunno-Bruscia, M., et al. (2017) Vibrio crassostreae, a benign oyster colonizer turned into a pathogen after plasmid acquisition. ISME J 11: 1043-1052.

Bruto, M., Labreuche, Y., James, A., Piel, D., Chenivesse, S., Petton, B., et al. (2018) Ancestral gene acquisition as the key to virulence potential in environmental \{Vibrio\} populations. ISME J 12: $2954-2966$.

Bull, J.J. and Lauring, A.S. (2014) Theory and Empiricism in Virulence Evolution. PLOS Pathog 10: e1004387. 
Chatterjee, D. and Chaudhuri, K. (2011) Association of cholera toxin with Vibrio cholerae outer membrane vesicles which are internalized by human intestinal epithelial cells. FEBS Lett $\mathbf{5 8 5}$ $1357-1362$.

Cianfanelli, F.R., Monlezun, L., and Coulthurst, S.J. (2016) Aim, Load, Fire: The Type VI Secretion System, a Bacterial Nanoweapon. Trends Microbiol 24: 51-62.

Cordero, O.X. and Polz, M.F. (2014) Explaining microbial genomic diversity in light of evolutionary ecology. Nat Rev Microbiol 12: 263-273.

Cota, I., Sánchez-Romero, M.A., Hernández, S.B., Pucciarelli, M.G., García-Del Portillo, F., and Casadesús, J. (2015) Epigenetic Control of Salmonella enterica O-Antigen Chain Length: A Tradeoff between Virulence and Bacteriophage Resistance. PLoS Genet 11: e1005667e1005667.

Cressler, C.E., McLEOD, D. V, Rozins, C., VAN DEN Hoogen, J., and Day, T. (2016) The adaptive evolution of virulence: a review of theoretical predictions and empirical tests. Parasitology 143 915-930.

Cui, Y., Yang, X., Didelot, X., Guo, C., Li, D., Yan, Y., et al. (2015) Epidemic Clones , Oceanic Gene Pools , and Eco-LD in the Free Living Marine Pathogen Vibrio parahaemolyticus. Mol Biol Evol 32: $1396-1410$

Cullen, T.W., Schofield, W.B., Barry, N.A., Putnam, E.E., Rundell, E.A., Trent, M.S., et al. (2015) Antimicrobial peptide resistance mediates resilience of prominent gut commensals during inflammation. Science (80- ) 347: 170 LP - 175. 
Demarre, G., Guérout, A.M., Matsumoto-Mashimo, C., Rowe-Magnus, D.A., Marlière, P., and Mazel, D. (2005) A new family of mobilizable suicide plasmids based on broad host range R388 plasmid (IncW) and RP4 plasmid (IncP $\alpha$ ) conjugative machineries and their cognate Escherichia coli host strains. Res Microbiol 156: 245-255.

Ferenci, T. (2016) Trade-off Mechanisms Shaping the Diversity of Bacteria. Trends Microbiol 24: 209223.

Friman, V.-P. and Buckling, A. (2014) Phages can constrain protist predation-driven attenuation of Pseudomonas aeruginosa virulence in multienemy communities. ISME J 8: 1820-1830.

Friman, V.-P., Lindstedt, C., Hiltunen, T., Laakso, J., and Mappes, J. (2009) Predation on multiple trophic levels shapes the evolution of pathogen virulence. PLoS One 4: e6761.

Gavin, H.E. and Satchell, K.J.F. (2015) MARTX toxins as effector delivery platforms. Pathog Dis 73: ftv092-ftv092.

Gonzalez, M., Gueguen, Y., Desserre, G., de Lorgeril, J., Romestand, B., and Bachère, E. (2007) Molecular characterization of two isoforms of defensin from hemocytes of the oyster Crassostrea gigas. Dev Comp Immunol 31: 332-339.

Ho, B.T., Basler, M., and Mekalanos, J.J. (2013) Type 6 secretion system-mediated immunity to type 4 secretion system-mediated gene transfer. Science (80-) 342: 250 LP - 253.

Lee, C.-T., Pajuelo, D., Llorens, A., Chen, Y.-H., Leiro, J.M., Padrós, F., et al. (2013) MARTX of Vibrio vulnificus biotype 2 is a virulence and survival factor. Environ Microbiol 15: 419-432.

Lehrer, R.I., Barton, A., and Ganz, T. (1988) Concurrent assessment of inner and outer membrane 
permeabilization and bacteriolysis in E. coli by multiple-wavelength spectrophotometry. J Immunol Methods 108: 153-158.

Levin, B.R. (1996) The evolution and maintenance of virulence in microparasites. Emerg Infect Dis 2: 93-102.

Lindell, K., Fahlgren, A., Hjerde, E., Willassen, N.-P., Fällman, M., and Milton, D.L. (2012) Lipopolysaccharide O-antigen prevents phagocytosis of Vibrio anguillarum by rainbow trout (Oncorhynchus mykiss) skin epithelial cells. PLoS One 7: e37678-e37678.

López-Pérez, M., Jayakumar, J.M., Haro-Moreno, J.M., Zaragoza-Solas, A., Reddi, G., RodriguezValera, F., et al. (2019) Evolutionary model of cluster divergence of the emergent marine pathogen Vibrio vulnificus: from genotype to ecotype. MBio 10: e02852-18.

Ma, A.T., McAuley, S., Pukatzki, S., and Mekalanos, J.J. (2009) Translocation of a Vibrio cholerae type VI secretion effector requires bacterial endocytosis by host cells. Cell Host Microbe 5: 234-243.

March, C., Cano, V., Moranta, D., Llobet, E., Pérez-Gutiérrez, C., Tomás, J.M., et al. (2013) Role of bacterial surface structures on the interaction of Klebsiella pneumoniae with phagocytes. PLoS One 8: e56847.

Matz, C. and Kjelleberg, S. (2005) Off the hook - how bacteria survive protozoan grazing. Trends Microbiol 13: 302-307.

Mikonranta, L., Friman, V.-P., and Laakso, J. (2012) Life history trade-offs and relaxed selection can decrease bacterial virulence in environmental reservoirs. PLoS One 7: e43801.

Pfaffl, M.W. (2001) A new mathematical model for relative quantification in real-time RT-PCR. 
Nucleic Acids Res 29: e45-e45.

Piel, D., Bruto, M., James, A., Labreuche, Y., Lambert, C., Janicot, A., et al. (2019) Selection of Vibrio crassostreae relies on a plasmid expressing a type 6 secretion system cytotoxic for host immune cells. Environ Microbio/ 0:

Pirofski, L. and Casadevall, A. (2012) Q and A: What is a pathogen? A question that begs the point. BMC Biol 10: 6.

Pupo, E. and Hardy, E. (2007) Isolation of smooth-type lipopolysaccharides to electrophoretic homogeneity. Electrophoresis 28: 2351-2357.

Raetz, C.R.H. and Whitfield, C. (2002) Lipopolysaccharide Endotoxins. Annu Rev Biochem 71: 635700.

Robino, E., Poirier, A.C., Amraoui, H., Le Bissonnais, S., Perret, A., Lopez-Joven, C., et al. (2019) Resistance of the oyster pathogen Vibrio tasmaniensis LGP32 against grazing by Vannella sp. marine amoeba involves Vsm and CopA virulence factors. Environ Microbio/ n/a:

Roig, F.J., González-candelas, F., Sanjuán, E., and Fouz, B. (2018) Phylogeny of Vibrio vulnificus from the analysis of the core-genome : implications for intra-species taxonomy.Front Microbio/ 8: 113.

Rosa, R.D., Santini, A., Fievet, J., Bulet, P., Destoumieux-Garzón, D., and Bachère, E. (2011) Big defensins, a diverse family of antimicrobial peptides that follows different patterns of expression in hemocytes of the oyster Crassostrea gigas. PLoS One 6: e25594-e25594.

Le Roux, F., Binesse, J., Saulnier, D., and Mazel, D. (2007) Construction of a Vibrio splendidus mutant 
lacking the metalloprotease gene vsm by use of a novel counterselectable suicide vector. Appl Environ Microbiol 73: 777-784.

Le Roux, F. and Blokesch, M. (2018) Eco-evolutionary dynamics linked to horizontal gene transfer in Vibrios. Annu Rev Microbiol 72: 89-110.

Le Roux, F., Labreuche, Y., Davis, B.M., Iqbal, N., Mangenot, S., Goarant, C., et al. (2011) Virulence of an emerging pathogenic lineage of Vibrio nigripulchritudo is dependent on two plasmids. Environ Microbiol 13: 296-306.

Le Roux, F., Wegner, K.M., Baker-Austin, C., Vezzulli, L., Osorio, C.R., Amaro, C., et al. (2015) The emergence of Vibrio pathogens in Europe: Ecology, evolution and pathogenesis (Paris, 11-12 March 2015). Front Microbiol 6: 1-8.

Le Roux, F., Wegner, K.M., and Polz, M.F. (2016) Oysters and Vibrios as a model for disease dynamics in wild animals. Trends Microbiol 24: 568-580.

Le Roux, F., Zouine, M., Chakroun, N., Binesse, J., Saulnier, D., Bouchier, C., et al. (2009) Genome sequence of Vibrio splendidus: an abundant planctonic marine species with a large genotypic diversity. Environ Microbiol 11: 1959-1970.

Rubio, T., Oyanedel, D., Labreuche, Y., Toulza, E., Luo, X., Bruto, M., et al. (2019) Species-specific mechanisms of cytotoxicity toward immune cells determine the successful outcome of Vibrio infections. Proc Natl Acad Sci 116: 14238.

Saar-Dover, R., Bitler, A., Nezer, R., Shmuel-Galia, L., Firon, A., Shimoni, E., et al. (2012) D-Alanylation of lipoteichoic acids confers resistance to cationic peptides in group B Streptococcus by 
increasing the cell wall density. PLOS Pathog 8: e1002891.

Sakib, S.N., Reddi, G., and Almagro-Moreno, S. (2018) Environmental role of pathogenic traits in Vibrio cholerae. J Bacteriol 200: 1-12.

Satchell, K.J.F. (2015) Multifunctional-autoprocessing repeats-in-toxin (MARTX) Toxins of Vibrios. Microbiol Spectr 3:.

Seed, K.D., Yen, M., Shapiro, B.J., Hilaire, I.J., Charles, R.C., Teng, J.E., et al. (2014) Evolutionary consequences of intra-patient phage predation on microbial populations. Elife 3: e03497e03497.

Seif, Y., Monk, J.M., Machado, H., Kavvas, E., and Palsson, B.O. (2019) Systems biology and pangenome of salmonella O-Antigens. MBio 10: e01247-19.

Shapiro, B.J., Levade, I., Kovacikova, G., Taylor, R.K., and Almagro-moreno, S. (2016) Origins of pandemic Vibrio cholerae from environmental gene pools. Nat Microbiol. 2:16240

Shapiro, B.J. and Polz, M.F. (2014) Ordering microbial diversity into ecologically and genetically cohesive units. Trends Microbiol 22: 235-247.

Simkovsky, R., Effner, E.E., Iglesias-Sánchez, M.J., and Golden, S.S. (2016) Mutations in novel lipopolysaccharide biogenesis genes confer resistance to amoebal grazing in Synechococcus elongatus. Appl Environ Microbiol 82: 2738-2750.

Sun, J., Wang, Lingling, Wu, Z., Han, S., Wang, Liyan, Li, M., et al. (2019) P38 is involved in immune response by regulating inflammatory cytokine expressions in the Pacific oyster Crassostrea gigas. Dev Comp Immunol 91: 108-114.

This article is protected by copyright. All rights reserved. 
Suquet, M., de Kermoysan, G., Araya, R.G., Queau, I., Lebrun, L., Le Souchu, P., and Mingant, C. (2009) Anesthesia in Pacific oyster, Crassostrea gigas. Aquat Living Resour 22: 29-34.

Takemura, A., Chien, D., and Polz, M. (2014) Associations and dynamics of Vibrionaceae in the environment, from the genus to the population level . Front Microbiol 5: 38.

Unterweger, D., Miyata, S.T., Bachmann, V., Brooks, T.M., Mullins, T., Kostiuk, B., et al. (2014) The Vibrio cholerae type VI secretion system employs diverse effector modules for intraspecific competition. Nat Commun 5: 3549.

Wildschutte, H., Preheim, S.P., Hernandez, Y., and Polz, M.F. (2010) O-antigen diversity and lateral transfer of the wbe region among Vibrio splendidus isolates. Environ Microbiol 12: 2977-2987.

Wildschutte, H., Wolfe, D.M., Tamewitz, A., and Lawrence, J.G. (2004) Protozoan predation, diversifying selection, and the evolution of antigenic diversity in Salmonella Proc Natl Acad Sci U S A 101: 10644 LP - 10649.

Zhang, D., lyer, L.M., and Aravind, L. (2011) A novel immunity system for bacterial nucleic acid degrading toxins and its recruitment in various eukaryotic and DNA viral systems. Nucleic Acids Res 39: 4532-4552. 
Figure legends.

Figure 1. V. splendidus \#23 shows moderate virulence in oyster experimental infections.

(A) Oyster survival was measured after injection with fifteen Vibrio strains representative of three ecological populations ( $\mathrm{x}$-axis). Strains from V. splendidus \#23 have been isolated from healthy oysters in spring, while strains from $V$. crassostreae and $V$. splendidus \#24 have been isolated from diseased oyster in summer. A dose of $10^{7} \mathrm{CFU}$ was injected intramuscularly to individual juvenile oysters and the percentage of survival was measured after 24 hours (y axis). A significantly higher oyster survival was observed for $V$. splendidus $\# 23$, which appeared less virulent than the two other populations tested, (ANOVA, $p<0.05$ and Tukey HSD test). Experiment was performed in duplicate and repeated once. (B) Kaplan Meier survival curves were generated for four strains of $V$. splendidus \#23 ( $2 \times 10^{7} \mathrm{CFU}$ per oyster). Mortalities were counted daily in two tanks containing 20 oysters for 6 days. Significant difference in survival curves (Log-rank $p$-value=0.0016, Bonferroni corrected for 10 comparisons) was recorded for strains 4G1_8 (non virulent) and 4G4_4 (moderately virulent). Data are representative of two independent experiments.

Figure 2. Oyster mortality in response to experimental infection with Vibrio wild type (wt) strains and isogenic mutants.

The $r t x A$, vipA and epsE genes were inactivated in V. splendidus \#23 strain 4G4_4. The wild type strains 4G4_4 (virulent) and 4G1_8 (non-virulent), and the 4G4_4 mutants were injected to 40 oysters $\left(2.10^{7}\right.$ CFU per animal). Data represent the survival percentage measured $24 \mathrm{~h}$ post injection in three independent experiments. Mean values are displayed \pm SD. Different letters indicate a significant difference between them (ANOVA, $p<0.05$ and Tukey HSD test). The $r$ txA-i and vipA-i mutants are 
attenuated (higher oyster survival) in contrast to the epsE-i mutant, which is more virulent that the wild type 4G4_4 strain (lower oyster survival).

Figure 3. Distinct gene contents in the wbe region are responsible for LPS variability in V. splendidus \#23

A- Silver-stained $4-15 \%$ polyacrylamide gel of LPS extracted from bacterial stationary phase cultures. Salmonella typhimurium Ra (rough type LPS lacking O-antigen) and Escherichia coli O111B4 (smooth type LPS containing O-antigen polysaccharides) are included as references. All strains from $V$. splendidus \#23 are smooth type (presence of O-antigen). Strain 4G1_8 shows an LPS profile distinct from the rest of $V$. splendidus \#23. The main differences between strains are highlighted with roman numerals. I shows different sizes of the Lipid A -oligosaccharide core (low size bands). II and III show differences in the O-antigen structure both at intermediate (II) and high size (III and IV). The epsE-i mutant shows important modifications of the O-antigen structure. B- Cytochrome $\mathrm{C}$ binding unraveling the effect of O-antigen structure on the interaction of bacteria with macromolecules. The ability of bacterial strains to bind cytochrome $\mathrm{C}$ is displayed. Data represent mean values of 3 independent experiments \pm SD. Different letters indicate a significant difference (ANOVA, $p<0.05$ and Tukey HSD test).

Figure 4. O-antigen structure influences bacterial fitness and immune recognition in oysters.

A- Competitive index $(\mathrm{Cl})$ between wild type strains and epsE-i mutant of $V$. splendidus. Randomly selected colonies isolated from injected animals were identified by PCR. The competitive index was calculated as the ratio of the strains in the input inoculum over the ratio of the strains in the output at 
$24 \mathrm{hpi}$. Each dot represents the $\log _{10}$ of the $\mathrm{Cl}$ obtained from colonies isolated from individual oysters. Means significantly higher than value 0 (t-test, $\mathrm{p}<0.01$ ) were considered as a competitive advantage of the strain. B- Relative expression of immune genes in response to Vibrio injection. 4 pools of 10 oysters were sampled 2 hours after being injected either with sterile seawater (SSW) or wild type (wt) and epsE-i mutant of $V$. splendidus ( $2 \times 10^{7} \mathrm{CFU} /$ animal). RNA was extracted from the 4 pools. For each pools, RT-qPCR was performed on immune genes to determine their expression relative to the elongation factor 1 alpha (EF1- $\alpha$ ). The $\Delta \Delta^{\text {ct }}$ method was used (Pfaffl, 2001). Data are presented as the mean \pm SD. Different letters indicate a significant difference between them (ANOVA, $p<0.05$ and Tukey HSD test).

Figure 5. Resistance to grazing by marine amoeba is dependent on LPS structure.

A- Bacterial resistance to grazing by Vannella sp. 1411 was assessed for V. splendidus strains 4G4_4 and epsE-i by measuring the fluorescence of the GFP-expressing bacteria after contact with amoebae over 12 days. The strain V. tasmaniensis LMG20012T was used as a grazing-susceptible control. Results show the mean of three technical replicates \pm SD. Data are representative of three independent experiments. Different letters indicate a significant difference, $p<0.001$ (RM-ANOVA). B- Amoeba growth was monitored at day 6,9 and 12 by manual counting under phase light microscopy. Each condition was counted in three technical replicates. The results shown are representative of three independent experiments. For each time point, different letters indicate a significant difference (ANOVA, $p<0.001$ and Tukey HSD test).

Figure S1. The rtxACHBDE cluster in V. splendidus \#23. 
A- The figure shows gene replacement between non-virulent and moderately virulent strains leading to loss/acquisition of the MARTX encoding genes cluster. B- MARTX effector domains. The domain abbreviations are: $\mathrm{Rtx}=$ Repeats-in toxin; $\mathrm{ACD}=$ Actin Cross-linking Domain; $\mathrm{ABH}=\alpha / \beta$ Hydrolase; $\mathrm{MCF}$ $=$ Makes Caterpillars Floppy; RRSP $=$ Ras/Rap1-specific endopeptidase CPD $=$ Cysteine Protease Domain (Satchell, 2015)

Figure S2. Growth curves of mutants versus wild type strains in LB NaCl medium.

Data show mean values of technical triplicates \pm SD.

Figure S3. Genetic organization of the T6SS cluster in V. splendidus \#23.

The figure shows gene replacements (in blue) between non-virulent and moderately virulent strains leading to loss/acquisition of a chromosomal T6SS-encoding gene cluster. Genes in green are specifically found in the non-virulent strain 4G1-8. Genes in red are specifically found in virulent strains and contain the T6SS genes. The gene cluster of the virulent strains is present on two contigs (genes GV4G44_380041 - GV4G44_380047 and GV4G44_320001 - GV4G44_320044). From the complete genome of $V$. tasmaniensis LGP32, which contains the same gene cluster, we found that genes GV4G44_380047 and GV4G44_320001 (hatched red genes) form a single large gene that is splitted in our assemblies due to numerous repeats.

Figure S4. Strains of $V$. splendidus \#23 are cytotoxic towards hemocytes.

Maximum cytotoxicity exerted by V. splendidus over oyster hemocytes in vitro. A hemocyte monolayer was exposed to vibrios at a MOI of 1:50 and the percentage of cell lysis was monitored by the SYTOX Green assay. (A) shows that the four strains of $V$. splendidus \#23 are cytotoxic towards hemocytes. 
Data are representative of five independent experiments. (B) shows that the vipA-i mutant derived from $V$. splendidus 4G4_4 does not show any attenuation of its cytotoxicity towards hemocytes, unlike the vipA1-I mutant derived from $V$. tasmaniensis LGP32. Data are representative of three independent experiments. Mean values of three technical replicates are displayed \pm SD. Identical letters indicate a non-significant difference (ANOVA, $p<0.05$ and Tukey HSD test).

Figure S5. Lipid A inferred structure does not differ between strains 4G1_8 and 4G4_4.

(A) Data show the MALDI-TOF spectra of 4G1_8 and 4G4_4 Lipid A. MALDI-TOF-MS analysis was performed in negative-ion [M-H]- / linear mode. A major Lipid A molecular species was observed at $\mathrm{m} / \mathrm{z}$ 1740.1-1740.7, which by analogy with $V$. cholerae Lipid A could be attributed to a hexa-acyl (6 FA) molecular species (Hankins et al., 2011, 2012), with one suggested exception i.e. the presence of nonhydroxylated 12:0 fatty acid at the secondary C3' position. As a consequence, no molecular species with Glycine substitution was found in either strain. Moreover, no substitution of phosphate groups with charged amino derivatives such as phosphoethanolamine or aminoarabinose could be inferred from our MS spectra. An additional peak, common to both strains was observed at m/z 1976.1-1977.4, which could be tentatively attributed to a hepta-acyl Lipid A molecular species (7 FA) carrying an additional $16: 0$ or $16: 1$ fatty acid. This molecular species appeared more intense in the virulent 4G4_4 than in the non-virulent 4G1_8. (B) Lipid A structure from Vibrio cholerae $\mathrm{O} 1$ adapted from Hankins et al. (2012), Fig.2. The upper panel shows the MALDI-TOF spectra of $V$. cholerae Lipid A with a major molecular species at $\mathrm{m} / \mathrm{z}$ 1756.1. The lowel panel shows the corresponding hexa-acyl molecular species (6 FA). Numbers indicate the number of carbons per acyl chain.

Figure S6. Inactivation of epsE in strains $4 \mathrm{G} 4 \_4$ and $4 \mathrm{D} 1 \_8$ generates the same 0 -antigen modifications and cytochrome $\mathrm{C}$ binding phenotype. 
(a) SDS PAGE electrophoresis of LPS extractions from bacterial cultures in stationary phase. (b) Percentage of cytochrome $\mathrm{C}$ bound to the bacterial surface of wild type strains and epsE-i isogenic mutants. Data represent mean values of 3 independent experiments \pm SD. Different letters indicate a significant difference (ANOVA, $p<0.05$ and Tukey HSD test).

Figure S7. Immune genes that do not respond to early infection by V. splendidus. 4 pools of 10 oysters were sampled $2 \mathrm{~h}$ after being injected either with sterile seawater (SSW) or vibrio strains $\left(2 \times 10^{7} \mathrm{CFU}\right.$ per animal). RNA was extracted from the 4 pools. For each pool, RT-qPCR was performed on immune genes to determine their expression relative to the elongation factor 1 alpha (EF1- $\alpha)$. The $\Delta \Delta^{\text {ct }}$ method was used (Pffafl., 2001). Data are presented as the mean \pm SD. Different letters indicate a significant difference (ANOVA, $p<0.05$ and Tukey HSD test).

Figure S8. Strain 4G4-4 do not show killing activity against $E$. coli ML35p in-vitro. Cells were coincubated in agar media for $4 \mathrm{~h}$ to allow cell to cell contact and T6SS mediated killing. Bars represent the mean CFU per milliliter of surviving $E$. coli from two replicates $( \pm S D)$. Means were compared by a Student's t-test ${ }^{\text {ns }}=p>0,05$ 
1 Table 1. Gene content of the wbe regions from $\boldsymbol{V}$. splendidus $\mathbf{4 G 4} \mathbf{4}, \mathbf{4 G 1} \mathbf{8}$, and $\boldsymbol{V}$. tasmaniensis LGP32. The epsE gene mutated in 4G4_4 appears in boldface.

2 Gene labels of strain 4G4_4 are used to represent the homolog genes of the moderately virulent strains of V. splendidus Pop\#23

\begin{tabular}{|c|c|c|c|c|c|c|c|c|}
\hline Pop\#23 & & & 4G1_8 & & & LGP32 & & \\
\hline ORF\# & Locus tag & Putative function or gene name & ORF\# & Locus tag & $\begin{array}{c}\% \mathrm{nt} \\
\text { similarity }\end{array}$ & ORF\# & Locus tag & $\begin{array}{c}\% \mathrm{nt} \\
\text { similarity }\end{array}$ \\
\hline 1 & GV4G44_v1_410010 & $g m h D$ & 1 & GV4G18_v1_20068 & 97.4 & 1 & VS_0201 & 94.9 \\
\hline 2 & GV4G44_V1_410009 & UDP-glucose 6-dehydrogenase & 2 & GV4G18_v1_20067 & 94.8 & & _ & \\
\hline 3 & GV4G44_V1_410008 & Trans criptional regulator & 3 & GV4G18_v1_20066 & 100 & 2 & VS_0202 & 98.1 \\
\hline 4 & GV4G44_v1_410007 & protein of unknown function & _ & & & & _- & \\
\hline 5 & GV4G44_v1_410006 & Peptidase & 4 & GV4G18_v1_20065 & 97.1 & 3 & VS_0203 & 89.6 \\
\hline 6 & GV4G44_V1_410005 & Serine acetyltransferase & 5 & GV4G18_v1_20064 & 100 & 4 & VS_0204 & 100 \\
\hline 7 & GV4G44_V1_410004 & $\mathrm{NAD}(\mathrm{P}) \mathrm{H}$-glyce rol-3-phosphate dehydrogenase & 6 & GV4G18_v1_20063 & 95.1 & 5 & VS_0205 & 95.4 \\
\hline 8 & GV4G44_V1_410003 & Export protein SecB & 7 & GV4G18_v1_20062 & 97.5 & 6 & VS_0206 & 98.1 \\
\hline 9 & GV4G44_v1_410002 & Rhodanese-related sulfurtransferase & 8 & GV4G18_v1_20061 & 99.3 & 7 & VS_0207 & 100 \\
\hline 10 & GV4G44_v1_370056 & protein of unknown function & _ & & & & _ & \\
\hline 11 & GV4G44_v1_370055 & GDP-mannose mannosyl hydrolase & _ & & & & - & \\
\hline 12 & GV4G44_v1_370054 & mannose-1-phosphate guanyltransferase & _ & & & & _ & \\
\hline 13 & GV4G44_v1_370053 & Phosphomannomutase & _ & & & & _- & \\
\hline 14 & GV4G44_v1_370052 & GDP-D-mannose dehydratase, NAD(P)-binding & _ & & & & _- & \\
\hline 15 & GV4G44_v1_370051 & Bifunctional GDP-fucose synthetase & - & & & & - & \\
\hline 16 & GV4G44_v1_370050 & O-unit flippase & - & & & & - & \\
\hline 17 & GV4G44_v1_370049 & CDP-4-dehydro-6-deoxy-D-glucose 3-dehydratase (fragment) & _ & & & & _ & \\
\hline 18 & GV4G44_v1_370048 & $\begin{array}{l}\text { Membra ne protein of unknown function; putative O-atigen } \\
\text { flippase }\end{array}$ & 15 & GV4G18_v1_20054 & 18.6 & & _- & \\
\hline 19 & GV4G44_v1_370047 & Puta tive glycosyl tra nsferase family 11 & - & & & & - & \\
\hline 20 & GV4G44_v1_370046 & Puta ti ve Uncharacterized glycosyltransferase HI_1578 & _ & & & & - & \\
\hline 21 & GV4G44_v1_370045 & Puta tive glycosyltransferase & 37 & GV4G18_v1_20032 & 26.5 & & _ & \\
\hline 22 & GV4G44_v1_370044 & Puta tive glycosyltransferase & _- & & & & _ & \\
\hline 23 & GV4G44_v1_370043 & Putative Glycosyl transferase, group 2 family epsE & _ & & & & _ & \\
\hline 24 & GV4G44_v1_370042 & Puta tive glycosiltranferase & 13 & GV4G18_v1_20056 & 29.2 & & _ & \\
\hline 25 & GV4G44_v1_370041 & O-antigen polymerase Wzy & & & & 19 & VS_0220 & 22.3 \\
\hline 26 & GV4G44_v1_370040 & Puta tive glycosyltransferase & 12 & GV4G18_v1_20057 & 37.3 & & _ & \\
\hline
\end{tabular}


GV4G44 v1 370037

Conserved membrane protein of unknown function

GV4G44_v1_370036

Outer membrane lipoprotein

GV4G44_v1_370035

Cons erved hypothetical protein

Lipoprotein

GV4G44 v1 37003

wza

G44_v1_370033

$w z b$

GV4G44 V1 370031

$w z c$

GV4G44_v1_370030

Cons erved protein of unknown function

protein of unknown function

$\mathrm{N}$-a ce tylmuramoyl-L-alanine a midase

Conserved protein of unknown function

Conserved protein of unknown function

Conserved protein of unknown function

HAD hydrolase, family IIA (fragment)

HAD hydrolase, family IIA (fragment)

protein of unknown function

protein of unknown function

puta tive CDP-glycerol:poly(Glycerophosphate)

glycerophosphotransferase

membrane protein of unknown function

Fa mily 2 glycosyltransferase

membrane protein of unknown function

cons erved protein of unknown function

puta tive glycosyl tra nsferase, group 1

Galactosyl-transferase

Puta tive a cetyltransferase

Peros amine synthetase (WeeJ)

Mannosyl-transferase

Cons erved protein of unknown function

Phosphoglyceromutase

GV4G18_v1_20030

GV4G18_V1_20029

GV4G18_V1_20028

GV4G18_V1_20027

GV4G18_v1_20026

GV4G18_v1_20025

GV4G18_V1_20024
VS_0208

VS_0209

VS_0210

VS_0212

VS_0213

VS_0214

VS_0215

$-$
95.7

85.3

93.9

90.5

93.8

92.2 
A

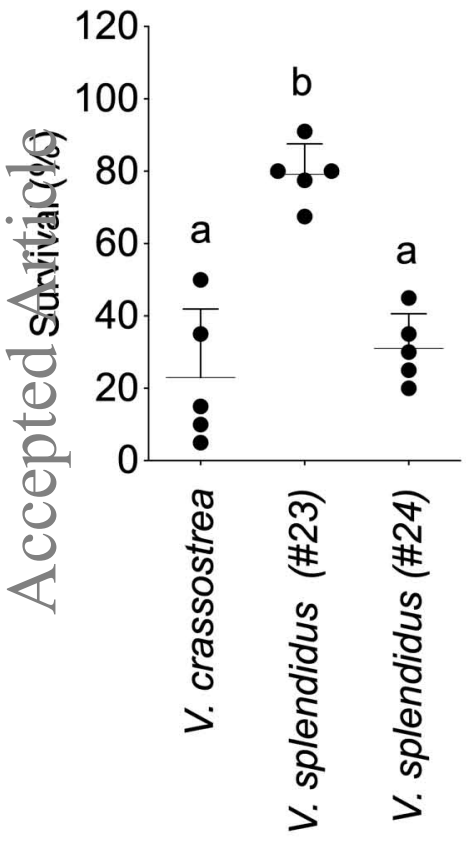

B

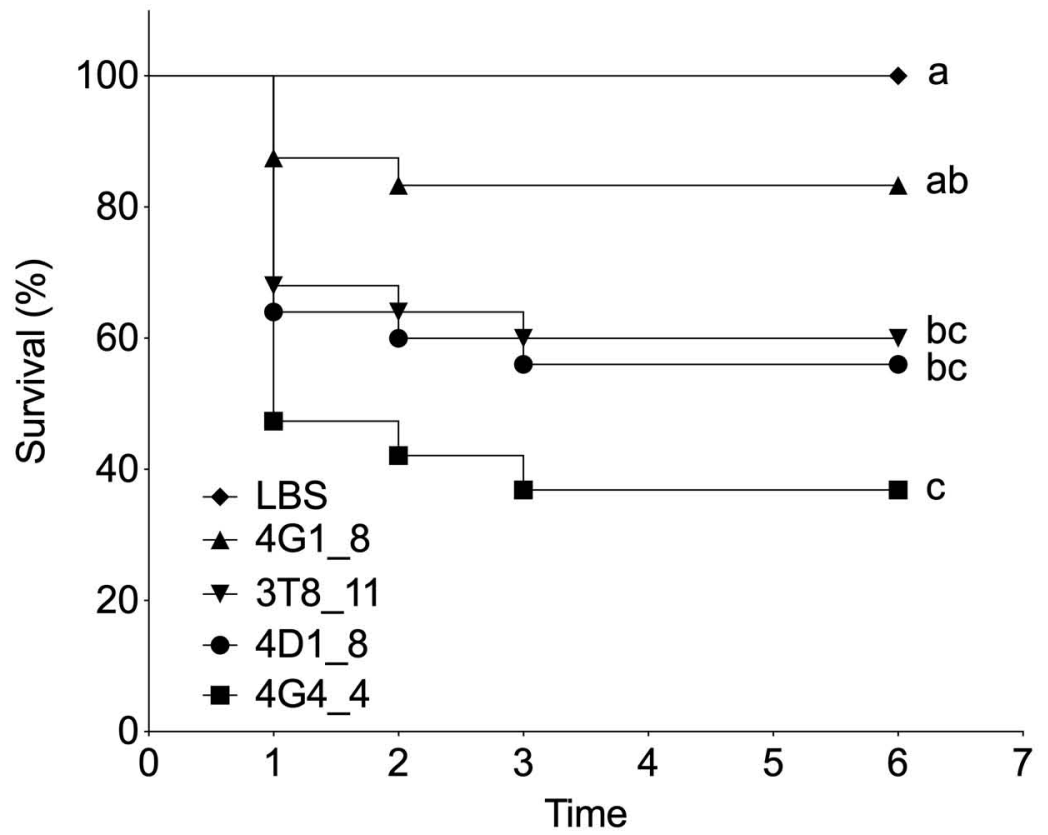




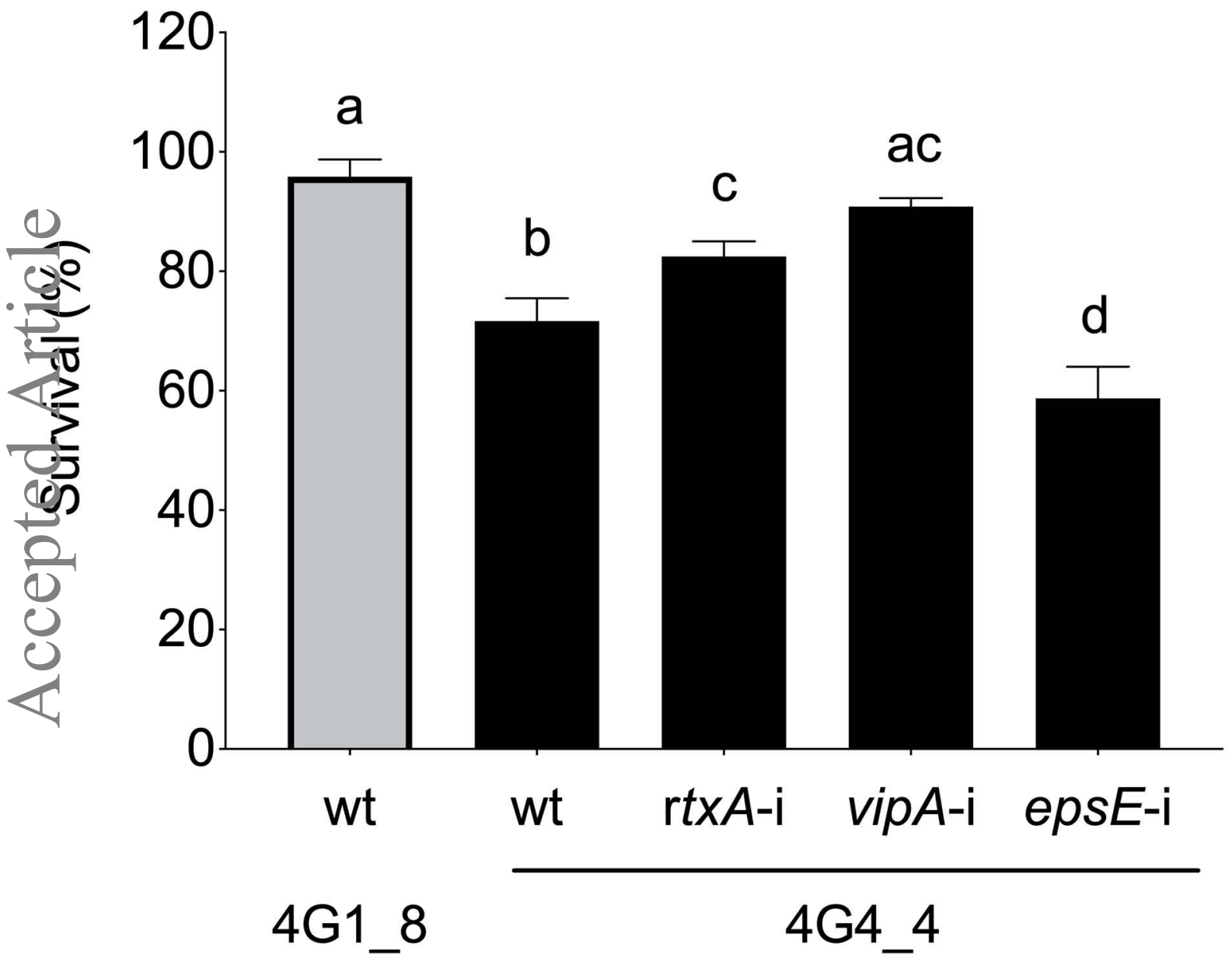



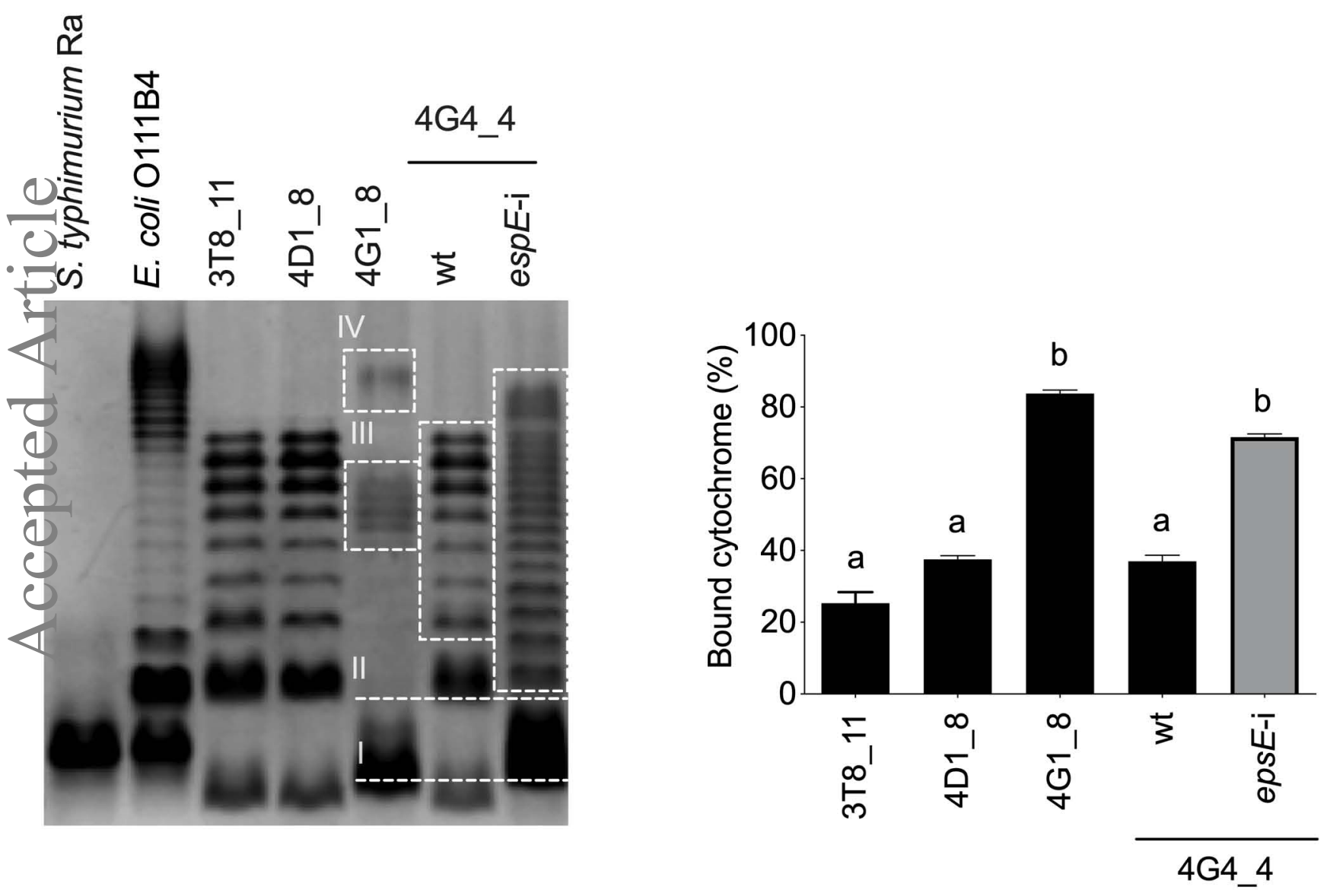
